\title{
College Students’ Attitudes towards Traditional and Nontraditional Parenting Roles: A Replication and Extension
}

\author{
Lauren Berger*, Nava Caluori, Maya Pintar, Samuel Sinemus, Lindsay Conley, Shahwar Salahuddin and Juliana Genovese
}

Faculty of Psychology, Skidmore College, USA

\begin{abstract}
The present study assessed the attitudes of 262 college students' attitudes toward different parenting styles by replicating and extending. It was hypothesized that traditional parents (i.e., working father, stay at home mother) would be viewed more positively than nontraditional parents (i.e., working mother, stay at home father). Results showed a non-significant interaction two-way ANOVA, $F(1,258)=3.413, p=0.066$. However, a significant main effect for employment status was found; partially supporting our hypothesis. Thus, regardless of the parent gender, participants viewed the employed parents as more positive than the stay at home parents. The most positive attitudes across all four vignettes were towards the working mother and the least positive were towards the stay-at-home mother. These findings are unexpected, different than the findings of; study replicated in the present study, and have important implications. Limitations, strengths, and future research are discussed.
\end{abstract}

Keywords: Traditional parenting; Working mother; Work-family; Stay at home father

\section{Introduction}

A clear distinction between "traditional" and "nontraditional" roles of parents is well established within American society and continues to hold true today [1,2]. The traditional father goes to work during the day and the traditional mother stays-at- home to tend to the house and the children [1]. While women are assumed to have communal characteristics such as concern for others and sociability, men are categorized as agentic and are assumed to hold traits such as independence, competence, and confidence $[3,4]$. These perceptions affect the responsibilities society deems most important and favorable for each sex. Men are evaluated based on their jobs, while women are viewed according to their families and their mothering nature [5]. The stereotype of women as communal and men as agentic has led to the general feeling that women should be caregivers for children while men take on the role of the breadwinner, or primary money maker.

Although research demonstrates that mothers are viewed as being caregivers and men as breadwinners, U.S. census information demonstrates a significant increase in the number of working mothers over the past 65 years. Whereas $23.8 \%$ of mothers with children under 18 years of age participated in the workforce in 1950 [6], 69.9\% of mothers with children under 18 years of age participated as of 2015 over $40 \%$ of mothers took on the role of the breadwinner and were financially supporting their families [7]. This image of a nontraditional mother at work breaks from established gender norms; thus, the image of a traditional mother is inconsistent with the reality of many families.

Meanwhile, fathers are also carving out a nontraditional niche. Fathers with children under 18 years of age had a workforce participation rate of $92.7 \%$ in 2015 , a slight decrease from $94.6 \%$ in 2003. In 2011, one in five fathers with children in preschool acted as the primary providers of child care while the mothers went to work. These fathers who pursue nontraditional communal roles are seen as breaking the norm. So, while families with a working father and stay-at-home mother (SAHM) depict traditional gender roles, families with a working mother and a SAHF (SAHF) depict nontraditional gender roles.

Society has historically placed great emphasis on the importance of traditional gender roles. Studies have shown that college students conform to these traditional gender norms in pursuing their aspirations and goals [8] found that college women were more inclined towards filling interpersonal needs, whereas college men were more geared towards accomplishing goals. Similarly, college seniors' with traditional views towards marriage preferred traditional career paths as well [9]. This research was conducted decades ago and may not reflect today's society and its varying ideas of gender roles. Despite this fluctuation, it appears that society continues to adhere to the traditionally gendered expectations for the roles prescribed to men and women [10].

\section{Social Role Theory}

The persistence and presences of traditional gender role norms for parents is best explained by Social Role Theory. Social Role Theory posits that gender role differences are based on the specific expectations and positions of men and women which are socialized within society. These gender roles serve to delineate what men and women are expected to do in society, simultaneously facilitating participation in society and forcing people into specific roles. This theory postulates that men tend to fill more agentic roles while women gravitate toward more communal roles, making gender differences more prominent.

Such norms, according to Social Role Theory, are reinforced by societal expectations for men and women to fill these respective roles. People attribute success in male-dominated occupations to malestereotypic traits, and to female-stereotypic traits in female-dominated occupations. Consequently, people who enter roles that are incongruent with the roles expected from their gender will face disapproval [11]. Thus, people believe certain genders will be more successful in certain fields and that people will negatively evaluate people who step outside of these socially prescribed bounds. Social Role Theory accounts for the perpetuation of gender roles and expectations.

*Corresponding author: Lauren Berger, PhD, Visting Assistant Professor, Faculty of Psychology, Skidmore College, USA, Tel: 518-527-6559; E-mail: Lberger@skidmore.edu

Received February 06, 2018; Accepted February 06, 2018; Published March 01, 2018

Citation: Berger, L., Caluori, N., Pintar, M., Sinemus, S., Conley, L, et al. (2018) College Students' Attitudes towards Traditional and Nontraditional Parenting Roles: A Replication and Extension. J Ment Disord Treat 4: 153. doi:10.4172/2471271X.1000153

Copyright: $\odot 2018$ Berger L, et al. This is an open-access article distributed under the terms of the Creative Commons Attribution License, which permits unrestricted use, distribution, and reproduction in any medium, provided the original author and source are credited. 
Social Role Theory has two slightly contrasting but coexisting foundations: an evolutionary perspective and a social role construction perspective. The evolutionary perspective holds that differing biological characteristics and different demands on men and women in historic times have resulted in gender role dichotomies. Specifically, gender differences arise from domains in which men and women have historically faced different challenges. These might be different physical demands that women and men faced due to different physical sizes, women's responsibility for bearing children, and other physical variations. Throughout history, women have played a much greater role in child rearing due to the substantial reproductive investment of pregnancy and childbirth, leaving men with the responsibility to provide essential human needs such as food and shelter [12]. Therefore, natural selection and human evolution are thought to have created a divide between work and family based on the physiological capacities of each gender. In return, the evolutionary perspective holds that the different evolved mechanisms of men and women are what lead people of different sexes to behave in specific way. The social role construction perspective, on the other hand, asserts that different societal structures and demands have led people to internalize differences in genders that would not be so pronounced otherwise Men have traditionally been given more power, which has led people to internalize and develop different ideal roles for men and women to fill.

Unsurprisingly, Social Role Theory has played a significant part in the development of parental roles. People engage in self-fulfilling prophecies placing themselves in roles oriented toward their prescribed gender roles. Additionally, people are quick to attribute genderconfirmative characteristics to others. For example, when people are presented with vignettes of men or women whose occupation is not specified, they assume that men have more agency and that women are more communal. In fact, when evaluating people's trait perceptions of parents, stay-at-home parents received higher communion and parenting effectiveness scores than working parents, whereas working parents were perceived as doing less parenting behaviors than stay-athome parents. In return, women, who are perceived as more communal would fill more communal role of caring for children and taking on the responsibilities of the home. Likewise, men, who are traditionally perceived as agentic, would fill the more agentic role of working and would therefore provide for the family. This pattern is supported by the perpetuating cycle of fulfilling socially expected roles that is posited by Social Role Theory.

Since society holds onto gendered roles so strongly, it would follow that people who deviate from these roles experience backlash. [13]. Accordingly, women who self-promote in professional fields and act agentically-a trait typically attributed to men-are liked less than women who behave more in line with traditionally female traits [14]. On the other side of the spectrum, stay-at-home-fathers reported negative responses from stay-at-home-mothers for their violation of the typical man-at-work role [15]. One specific study that tested negative attitudes and responses towards stay-at-home and working parents, showed that participants held a negative bias toward nontraditional parents' relative to their traditional counterparts. Other studies with different methods have been conducted and have found the same results, showing the pervasiveness of this phenomenon in society. These are discussed below.

\section{Study of Replication and Supporting Studies}

A wealth of other research has corroborated findings indicating that traditional parents are perceived positively while nontraditional parents are perceived negatively. Affirmations for the traditional female role of caregiver can be seen in the belief that SAHMs are the only acceptable parental, as their presence in the home is natural and acceptable [16]. A traditional mother stays at home with the children but also spends quality time with them "to ensure proper development" both physically and psychologically. "Intensive mothering" posits that mothers hold primary responsibility for childcare [16]. As a result of this ideology, mothers have been classified as the "real, natural and universal" caregiver Arendell more importantly as the only acceptable caregiver [17]. This perception completely isolates fathers from the role of primary caregiver.

While the "intensive mother" personifies traditional values, the working mother is defined as career-oriented and nontraditional. Culturally, women are viewed as being incapable of having a full-time career while simultaneously taking care of their children. It is commonly held that working leads mothers to prioritize work over their children. Working mothers are also at a disadvantage because they are assumed to have less of a relationship with their children [18]. These mothers have been characterized in the media as "selfish," "arrogant," "angry," and "resisting real femininity".

Women have reported negative reactions from others for being working mothers. They have encountered stigma and isolation, and reported feeling judged by other mothers for not participating in events with their child. For example found that women who worked full-time after a child's birth were rated as less communal and seen more negatively than women who either stopped working until the child was in first grade or stopped working all together. Mothers were also rated more negatively if they worked for personal rather than financial reasons. Etaugh and Folger [19] compared perceptions of mothers and fathers in the traditionally male role of going to work. Participants rated fathers working full-time as more competent than fathers working part-time, but did not afford full-time working mothers the same benefit. Further, both mothers and fathers working full-time were seen as less nurturing, but these effects were more pronounced for women. Similarly Riggs [20] found that parents who stayed home were seen as more communal while those who worked were seen as more agentic. In accordance with gender norms, participants reported liking nontraditional working mothers less than their traditional counterparts. Additionally, working mothers are rated as worse, less effective parents than working fathers when employed in traditionally male jobs, when their success is evident, and when working for personal instead of financial reasons [21]. These findings all indicate that, as predicted by social role theory, society does not like it when women break their communal gender norms.

SAHFs are subject to judgemental perceptions as well. They are prescribed stereotypes such as, lazy, irresponsible, and unmanly. Consequently, SAHFs are disrespected and considered a burden because they do not financially support their families or provide the same type of love that mothers can. Models of fatherhood suggest that fathers are incapable of being the primary caregiver. A common view is that they are unhelpful and unavailable when needed most. The mother is perceived as the active parent, while the father is viewed as the "helper" and is labeled "Mr. Mom". Mothers are best fit to provide for their children due to the fact that society views fathers as incapable of caregiving because they lack the innate nurturing capabilities of a traditional mother [22].

Research demonstrates that SAHFs experience significant backlash for their nontraditional roles. In a study assessing attitudes toward SAHFs (SAHFs), $44.9 \%$ of the SAHFs reported experiencing negative reactions and stigmatization from other adults. This was found despite a $65 \%$ increase in SAHFs, from. Still, despite the increasing number 
of men taking on the role as primary caregivers, this break from tradition is still not viewed as socially acceptable, nor do people rate it positively Studies have shown that neither mothers nor fathers can escape criticism when taking on a nontraditional role. However, this criticism is generally not based off of a full picture that takes all factors of a parent's choice into consideration. Many studies demonstrate the importance of taking multiple factors, such as gender, work, family, relationships and identity, into consideration Fathers' decisions to stayat-home include factors such as loss of job, illness, a spouse's higher salary, children needing a caregiver, and/or working from home. The same can be said for women, as far as choosing to work full-time. These non-traditional roles are not out of spite to society but, rather, a product of a variety of variables.

One major influence, and in fact the foundation of the present study, The initial study showed that individuals had more negative attitudes toward nontraditional parents (i.e., SAHF, working mother) than traditional parents (i.e., SAHM, working father). In other words, mothers who chose to go to work and fathers that chose to stay at home were viewed more negatively than traditional parents. The SAHF was perceived most negatively overall. The findings from are consistent with a host of similar studies highlighting the pervasive nature of prescriptive gender stereotypes for parents [23] and how violating these prescriptions, while maintaining a productive lifestyle, can have negative ramifications on cognitive and societal well-being.

Notably, research has primarily focused on the general population and did not target specific ages or generational differences. Thus, the present study aimed to better understand and assess college students attitudes towards nontraditional and traditional parents to determine if they differed from the general population. Studies examining samples of college students have demonstrated that education and exposure to peers' alternative ideologies can shift attitudes towards being more accepting of nontraditional parents [24]. However, based on the pervasive nature of Social Role Theory and gender role stereotyping, as well as the purpose of replication, it was expected that the findings would be consistent.

In replication of Brescoll and Uhlmann [1] some measures were added in order to gain a more detailed sense of why people might respond to traditional versus nontraditional parents differently. We hypothesized traditional parents would be seen more positively than nontraditional parents. Specifically, the order of positive attitudes would be highest for the stay at home mother, second, the working father, thirdly, the working mother, with the least positive attitudes towards the stay at home father.

\section{Method}

\section{Participants}

To determine the desirable sample size given the research design, we performed an a priori statistical power analysis [25]. Thus, a sample of at least 180 participants with a medium effect size, Type I error rate of $\alpha=0.05$, was necessary to have power meet 0.80 .

Participants were 262 undergraduate college students enrolled in a four-year program in the United States $\left(\mathrm{M}_{\text {age }}=20.64, \mathrm{SD}=1.37\right)$. They were sampled through posting a link to the survey on social media websites (e.g., Facebook and Twitter). Participants were $32.4 \%$ male and $66.8 \%$ female, and $0.8 \%$ identified as "other." Concerning race and ethnicity, $63 \%$ of participants identified as White, $12.2 \%$ as Asian, $9.2 \%$ as Black or African American, $6.5 \%$ as Hispanic or Latino/a, 5.3\% as multiracial, and 3.8\% identified as "other" (including American-Indian,
Pacific Islander, and Alaskan Native). The majority of participants (40.3\%) indicated that they studied social sciences, $14.3 \%$ studied natural science, $13.2 \%$ were double-majors, $8.1 \%$ studied quantitative reasoning and $8.1 \%$ studied arts, $6.6 \%$ studied the humanities, $2.7 \%$ had self-declared majors, $1.9 \%$ studied Non-Western topics and $1.9 \%$ studied Education, and $2.8 \%$ studied another subject (education or foreign language). Noteworthy, $49.4 \%$ of participants were seniors in college, $33.3 \%$ were juniors, $11.9 \%$ were sophomores, and $5 \%$ were freshmen. Most participants were born in the United States at $86.6 \%$. In regard to socioeconomic status, $43.7 \%$ identified as upper-middle class, $27.6 \%$ as middle, $16.9 \%$ as upper, $11.1 \%$ as lower middle, and $0.8 \%$ as lower class. Thus, the majority of the samples were female upperclassman from at least a middle class background.

\section{Design and Materials}

This study was administered using Qualtrics Survey Software. Participants accessed the survey through an online link and completed it on their personal computers or smartphones. The vignettes used were adapted from Brescoll and Uhlmann [1] and edited for the purposes of this experiment. All the vignettes were about a husband and wife deciding who would work and who would stay home after the birth of their second child. The vignettes were identically worded except that the parents in each role were changed for each of the four vignettes. Vignette one presented John going to work (traditional), vignette two presented Jennifer going to work (nontraditional), vignette three presented John staying at home (nontraditional), and vignette four presented Jennifer staying at home (traditional). Wording from Brescoll and Uhlmann [1] hat made the choice to work/stay home seem like one person's decision was removed in order to reduce any potential biasing effects of it not being a mutual decision.

Eleven follow-up questions assessed participants' opinions toward the target parent in whatever vignette they were assigned to. They were questions such as "--- is selfish" and "--- is a good parent." There were nine questions adapted from Brescoll and Uhlmann [1], however they used a "feeling thermometer" towards the parent ranging from 1-100 which we adapted to a 1 to 9 scale. Additionally, two items were added that assessed participant's ratings of whether they would do the same thing as the parent in the vignette, their predictions of how the target parent's friends would react. Questions were asked on a likert-type scale ranging from 1 (strongly disagree) to 9 (strongly agree). There was also a demographics section of the questionnaire that assessed participants' family structures, socio-economic status, year in school, major and other information related to the participant. The experiment was between-subjects and had a 2 (parent gender) X 2 (parent at work or at home) design.

\section{Procedure}

The study was approved by the Participant Review Board at a small liberal arts college. Participants were recruited via convenience sampling through social media. The data collection was a course requirement for an upper level social psychology research course at a small liberal arts college. The participants were sent to the survey website using a survey software called Qualtrics.com. They were first presented with an informed consent form and after indicating that they complied with and understood the consent form, they were assigned to one of four vignettes. The assignment was determined by which vignette the student in the social psychology course created for the Qualtrics website. Participants then completed the opinions measures based on their appraisal of the target parent in that vignette. Afterwards, they filled out the demographics questionnaire. After completing the 
demographics, they were debriefed and the survey ended. The total completion time ranged from 8 to 15 minutes. A total of 62 participants were assigned to the working father vignette, 63 participants to the working mother vignette, 74 participants for the SAHF vignette, and 63 participants for the stay at home mother vignette.

\section{Results}

\section{Descriptives}

Participants in each condition described their upbringings and family background. It appeared that there were no notable differences among the four groups. The majority (83.2\%) of participants grew up with both biological parents in their household, $6.5 \%$ grew up with both biological and step-parents, $5.3 \%$ with a single mother, $1.9 \%$ with relatives, $1.5 \%$ with a single father, $0.8 \%$ with guardians, and $0.4 \%$ with foster care. The highest levels of education attained by the participants' mothers/guardians were $33.6 \%$ bachelor's degree, $23.7 \%$ associate's degree, $13.7 \%$ master's degree, $10.7 \%$ some college, $7.6 \%$ high school diploma or GED, 5.3\% less than high school, and 5.3\% doctoral degree. The highest level of education attained by the participants' fathers/ guardians were $26.4 \%$ bachelor's degree, $26.1 \%$ master's degree, $22.2 \%$ associate's degree, $9.6 \%$ high school diploma or GED, $6.1 \%$ some college, 5.4\% less than high school, and $4.2 \%$ doctoral degree. During early childhood, $48.9 \%$ of participants' mothers were employed, $45.4 \%$ stayed at home, and $5.7 \%$ were listed as "other" or "N/A." During early childhood, $87.8 \%$ of participants' fathers were employed, $5.3 \%$ stayed at home (a total of 13 participants reported their fathers staying at home), and $6.8 \%$ were listed as "other" or "N/A."

The participants were asked two questions relating to the individual in the vignette's reason for employment. One question asked about how much the participant agreed with the parent's decision if it were for financial need and the second asked about personal fulfillment. Interestingly, every group's mean was higher for financial need as opposed to personal fulfillment except the stay at home mother vignette $\left(\mathrm{M}_{\text {personalfulfillment }}=6.61, \mathrm{SD}=2.38 ; \mathrm{M}_{\text {financialneed }}=6.10, \mathrm{SD}=2.58\right)$. The working father vignette group reported a mean of $6.47(\mathrm{SD}=2.54)$ for personal fulfillment and a mean of 7.85 for financial need $(\mathrm{SD}=2.08)$. The working mother vignette reported a mean of 7.30 for personal fulfillment $(\mathrm{SD}=1.78)$ and a mean of $8.28(\mathrm{SD}=1.30)$ for financial need. For the stay at home father vignette, participants reported a mean of 6.95 for personal fulfillment $(\mathrm{SD}=2.09)$ and a mean of $7.36(\mathrm{SD}=1.99)$ for financial need.

Participants were also asked to state how much they agreed with the following statement "If I was I would make the same decision [to work or stay at home]". Participants assigned to the stay at home mother vignette reported the lowest level of agreement with this statement $(\mathrm{M}=4.77, \mathrm{SD}=2.57)$. The second lowest level of agreement was the stay at home father vignette $(M=5.18, S D=2.50)$. Both working parent vignettes had higher and similar agreements $\left(M_{\text {working }}\right.$ ${ }_{\text {mother }}=6.58, \mathrm{SD}=2.25 ; \mathrm{M}_{\text {working father }}=6.60, \mathrm{SD}=2.32$ ). Lastly, participants were asked how they felt toward the parent in the vignette. The most positive feelings ( 1 being cold and 9 being warm) were held towards the working mother $(\mathrm{M}=7.38, \mathrm{SD}=1.70)$; then the stay at home father group $(M=7.25, S D=1.64)$; the stay at home mother group $(M=6.77$, $\mathrm{SD}=1.60)$; and the least positive feelings were towards the working father $(M=6.37, S D=1.70)$.

\section{Results}

Two-way analysis of variance (ANOVA) between subjects was conducted to examine the effects of the gender of the parent and employment status on attitudes of the participants. The two-way ANOVA revealed a non-significant interaction effect between gender and employment status of the parent, $F(1,258)=3.413, p=0.066$, $\mathrm{h}_{\mathrm{p}}{ }^{2}=0.035$. The hypothesis was partially supported by a significant main effect of employment status, regardless of the gender, $\mathrm{F}(1,258)=37.216$, $\mathrm{p}<0.001$. There was a non-significant main effect for gender of the parent, $\mathrm{F}(1,258)=0.495, \mathrm{p}=0.482$. Participants held the most positive attitudes towards Jennifer at work (working mother; $M=79.78$, $\mathrm{SD}=12.94$, with the second most positive attitudes being towards John at work (working father; $\mathrm{M}=75.98, \mathrm{SD}=11.82$ ). The attitudes towards John and Jennifer at work were significantly more positive than John at home (stay at home father; $\mathrm{M}=69.65, \mathrm{SD}=10.78$ ), and Jennifer at home (stay at home mother; $\mathrm{M}=67.95, \mathrm{SD}=12.60$ ). Regardless of the gender of the parent, more positive attitudes were held towards those who were employed versus stayed at home. Ultimately, the vignette with the stay at home mother resulted in the most negative attitudes, an unexpected finding.

Being that the sample was predominantly female, a secondary analysis was run to test participant gender differences within each vignette. There were no significant participant gender differences within the working father, stay at home father, and stay at home mother vignettes. However, female participants assigned to the working mother vignette had significantly more positive attitudes than male participants (t $(61)=-2.852, \mathrm{p}=0.006)$. The mean attitude towards the working mother, for female participants, was $\mathrm{M}=83.29, \mathrm{SD}=9.68$, whereas male participants' attitudes were lower $(M=74.18, S D=15.68)$. Interestingly, female participants had the most negative attitudes towards the stay at home mothers $(M=67.81, S D=12.20)$ and male participants held the most positive attitudes towards the working father $(M=79.06$, $\mathrm{SD}=12.16)$.

\section{Discussion}

The present study hypothesized that undergraduate students would align favorably with conventional family frameworks and negatively evaluate atypical parenting styles. Therefore, we hypothesized that a sample of undergraduate students would present a response bias in favor of a traditional parenting paradigm in the form of their selfreported attitudes and opinions. Our main findings were surprising. Our hypothesis was partially supported because approval for John in the traditional working role was stronger than that for John in the nontraditional stay-at-home role. However, our results concerning the parenting roles of mothers did not support our research hypothesis. Instead, the data revealed a preference towards the role of working mothers and negative evaluations of the traditional role of SAHMs. Furthermore, the data indicates that the vignette describing the working mother was perceived more positively than the traditional working father role. These findings are striking because they are inconsistent with previous research and indicate a shift in attitudes particularly among college students. Supporting and extending these results are findings that students become more accepting of nontraditional gender roles during college. Bryant suggested that exposure to diversity, women's studies courses, and peers were possible explanations for the increased approval of nontraditional roles.

The majority of participants in our study were seniors $(49.4 \%)$ and women $(66.8 \%)$, and responses indicated positive attitudes toward working parents. It is clear that educational allows for individual expression and encourages students to question underlying societal and cultural assumptions of gender roles. Based on the specifics of our sample, two important sources of societal shift towards more egalitarian 
gender roles may include levels of education completed by the parents as well as the mother's employment status within our sample $(52.6 \%$ mothers obtained at least a bachelor's degree, and $56.7 \%$ of fathers obtained at least a bachelor's degree). While the college students were in support of nontraditional roles for mothers, they supported traditional roles of fathers. This result supported only part of our hypothesis. College student's upbringing and exposure may contribute to their awareness of the gender inequality. Thus, their education can be an underlying influence in the formation of the differences in attitudes.

A side from the education level of children and parents, there are several other explanations for the perceptual shift on parenting roles. Women, according to Eagly et al. [26] embody both feminine and masculine characteristics, which allow them to acceptably occupy both traditional and nontraditional roles. SAHFs may have been more negatively rated (compared to the nontraditional role of working mothers) in our study because of the drop in social status by adopting traditional feminine roles. In contrast, working women may have been more positively rated because they adopt a more masculine, high status role, which helps them gain a more elevated social status. The fact that college students are more supportive of women working than women staying at home could indicate a shift in society's perception regarding the natural role of women. The stronger approval ratings for the working mother as opposed to the working father could be a reaction to the long-standing norm that women should stay at home while men work, being an over-correction as attitudes shift to being more accepting of women at work. Although these findings are not consistent with, their implications suggest a societal modification of prescribed parenting roles.

The late 20th and early 21 st centuries signify the extreme changes that altered the lives, work, relationships, and family roles of parents in the United States [27]. One possible explanation of the societal shift is believed to be the progressive decline in women occupying traditional parenting roles, as homemakers and primary caregivers, is a result of feminism [28]. Thus, SAHMs are stigmatized by society for not being employed outside of the home. Because of these new and negative connotations associated with SAHMs, women are increasingly entering into the public sphere and decreasing their foothold in domesticity. This trend is supported by the findings indicating that $70.1 \%$ of mothers with a child under the age of eighteen were employed. present the idea that the roles of women and men have started to overlap because of the increase of women in the paid labor force. From 1950 to 1998, women's participation in the labor face has increased from $34 \%$ to $60 \%$, while men's involvement diminished from $86 \%$ to $75 \%$. It is proposed that women's roles have altered to incorporate domestic responsibilities as well as labor characteristics. However, men do not show a significant increase in occupying female-dominated roles to the same degree that women have entered the male-dominated occupations. Therefore, the findings in this study not only suggest that the population of women in the workforce is growing, but that it may be more socially acceptable for them to take on masculine working roles due to the finding that women have the ability to personify both masculine and feminine traits. found that there is an increase in the perception of women's masculine characteristics, which they relate to the increase and more accepted entry of women in male-dominated occupations. This reversal of gender roles, is evident in recently married couples. From 1996 to 2008 the number of SAHFs has tripled from 49,000 to 158,000 while a competing number of wives and/or mothers are pursuing traditionally masculine role of breadwinner. Society has allocated the roles of men into an idle and stigmatized category where men belong in masculine related roles and not those associated with roles deemed feminine. As a result, men have a more difficult time supporting nontraditional gender roles. It is clear that women's stereotypes are more dynamic compared to men's, which remain relatively unchanged and traditional Liss and Erchull [28] Therefore, this may explain our findings of John at work being more positively viewed than John staying at home and why there was so much support for Jennifer working outside of the home. Research supports this, as they found that women endorsed egalitarian gender roles more so than men, suggesting that men have more negative perceptions of nontraditional gender roles, compared to the egalitarian views of women.

\section{Strengths and Limitations}

The findings in the current study should be considered within the context of both strengths and limitations. Replication and extension studies are considered highly beneficial contributions to the further development of theory and research $[29,30]$. By replicating and extending a rigorous study, we applied existing theory to a college student population to determine generalizability of a more specific population. By recruiting participants enrolled in four-year college programs, we were able to observe perceptions of traditional and nontraditional parenting from this specific population. Furthermore, Brescoll and Uhlmann [1] had stressed the importance of having a more diverse sample in order to better represent racial and ethnic diverse attitudes towards traditional and nontraditional parenting. The present study, although purposefully college students, had a more diverse sample than the sample also promoting increased generalizability.

Additionally, items utilized to test for attitudes in our questionnaire were previously factor analyzed, increasing our construct validity which confirmed that we were measuring what we claimed to. Although the study replicated, the vignettes were modified as well as the items capturing the attitudes of the participants to further decrease demand characteristics and socially desirable responses. Lastly, the present study exceeded the a priori desired sample size to achieve a power level of 0.80 . Thus, increasing the strength of the findings as well as the generalizability of the study.

There were also noteworthy limitations within the study. First, the sample was $63 \%$ Caucasian and $66.8 \%$ female from a moderate to high SES background. Replication of this study with a broader sample of undergraduate students is recommended. Although participants identified if they were born in the United States, and were required to be enrolled in a U.S. four year college to participate in the study, here was no demographic question asking their country of origin, limiting how widespread the sample might be. Additionally, the items were not randomly distributed and immediately followed the reading of the vignettes, making it likely that they created demand characteristics, subsequently biasing participant responses. There may have been extraneous factors that had a greater impact on a person's attitude that we did not account for, such as exposure to nontraditional families among friends, or family type representation through media consumption. Future research should incorporate covariates and highlight potential confounds.

The present study limited its scope to focus solely on a heterosexual couple, John and Jennifer. It is important to note that the study had a specific definition of nontraditional parenting as a working mother and a SAHF. Future research might want to expand the definition of nontraditional parenting, such as focusing on the LGBT+ community. In a study conducted by Liss and Erchull [28], they excluded homosexual couples due to additional considerations unique to same sex couples. Therefore, further theorizing and developing should occur 
Citation: Berger, L., Caluori, N., Pintar, M., Sinemus, S., Conley, L, et al. (2018) College Students' Attitudes towards Traditional and Nontraditional Parenting Roles: A Replication and Extension. J Ment Disord Treat 4: 153. doi:10.4172/2471-271X.1000153

Page 6 of 7

when expanding the study of nontraditional parenting roles. However, future research should include a parenting paradigm inclusive of all family frameworks, reflective of the evolving family unit.

\section{Implications for Future Research}

Future research should continue to evaluate shifting attitudes towards traditional and nontraditional parenting. If individuals are becoming more accepting of nontraditional parenting roles, perhaps stereotypes in the workplace will decrease as well. Regardless, future research should focus on further replication in order to address the possible causes of shifts in attitudes toward nontraditional parenting since our findings differed from. In order to strengthen validity, future research should consider utilizing random assignment of the vignettes to help limit any additional confounds.

Additionally, replications of this study should examine these parameters cross-sectionally to discern if the effects are generational or are representational of the whole population. The results from this study were based off of the responses from college students, and therefore come from a relatively young sample. Conducting this research across varying age groups would indicate whether these results stem from the liberal ideations of the younger generation or represent a shift in society's perceptions of nontraditional parenting roles.

Previous research has implied that undergraduate women who identified more strongly with a feminist perspective, were more likely to have egalitarian expectations for their future marital and parenting roles [29,31] Specifically, women's perceptions about their expected roles change when anticipating motherhood. Future research should continue to explore the contribution of feminist ideations and values on differences in attitudes towards traditional and nontraditional parenting roles.

The present study showed more positive ratings toward the nontraditional parenting of a working mother but in line with the research of Liss and Erchull [28], the attitudes may have been more traditional if we had used a sample that was closer to anticipated parenthood. Research has showed that attitudes tend to shift toward more traditional roles when nearing parenthood [31]. Therefore, future research may want to compare the perceptions of nontraditional versus traditional parenting between generations at different life stages.

Future research could also observe the environment in which an individual is born and grows up in coupled with the characteristics of their family background, particularly as moderating and mediating variables [32]. It has been observed that children raised with high parental involvement had more positive attitudes towards nontraditional parenting than children who had less parental involvement during their development.

\section{Conclusion}

Modern perceptions of gender roles are at a crucial point in their development. Some people are pushing for more progressive interpretations of what is acceptable and advocating for the deconstruction of gender norms. Parenting roles have always been strictly defined and influenced by gender. Looking at a more specific population, such as college students, provided us a deeper exploration of attitudes and a better understanding of how perceptions shift depending upon age and educational exposure. The results of this experiment have significant implications for today's society and may indicate change in a more egalitarian direction. Overall, our findings provide significant insight to the evolving area of perceptions towards traditional and nontraditional parenting. If future studies find results consistent with this study, then it can be argued that college students' attitudes towards traditional and nontraditional parenting roles are shifting toward more liberal perceptions. In general, future research should help to understand why there are still negative [33] perceptions towards fathers as the stay-at-home parent, and when in development we should teach children about gender roles, if at all.

\section{References}

1. Brescoll V, Uhlman EL (2005) Attitudes toward Traditional and Nontraditional Parents. Psychology of Women Quarterly 29: 436-445.

2. Koenig AM, Eagly AH (2014) Evidence for the social role theory of stereotype content: Observations of groups' roles shape stereotypes. Journal of Personality and Social Psychology 107: 371-392.

3. Bridges JS, Etaugh C, Barnes-Farrell J (2002) Trait judgements of stay-athome and employed parents: A function of social role and/or shifting standards? Psychology of Women Quarterly 26: 140-150.

4. Diekman AB, Eagly AH (2000) Stereotypes as Dynamic Constructs: Women and Men of the Past, Present, and Future. Personality and Social Psychology Bulletin 26: 1171-1188.

5. Feree MM (1990) Beyond separate spheres: Feminism and family research Journal of Marriage and Family 52: 866-884.

6. U.S. Bureau of labor Statistics (2015) Employment Characteristics of Families Summary.

7. Council of Economic Advisers (2014). Nine Facts About American Work Life

8. Bardwick J (1971) Psychology of Women: A study of biocultural conflicts. New York: Harper \& Row.

9. Richardson MS (1974) The dimensions of career and work orientation in college women. Journal of Vocational Behavior 5: 161-172.

10. Petroski DJ, Edley PP (2006) Stay-at-home-fathers: Masculinity, family, work and gender stereotypes. Electronic Journal of Communication 16: 3-4.

11. Eagly AH, Karau SJ (2002) Role congruity theory of prejudice toward female leaders. Psychological Review 109: 573-598.

12. Bleske Rechek A, Fuerstenberg EA, Harris HD, Ryan DE (2011) Men and women, work and family: A test of competing perspectives. Journal of Social, Evolutionary, And Cultural Psychology 5: 275-292.

13. Mills MJ (2015) Gender and the work-family experience: An intersection of two domains. Cham, Switzerland: Springer International Publishing.

14. Rudman LA, Glick $P$ (1999) Feminized management and backlash toward agentic women: The hidden costs to women of a kinder, gentler image of middle-managers. Journal of Personality and Social Psychology 77: 10041010.

15. Rochlen AB, McKelley RA, Whittaker TA (2010) Stay-at-home fathers' reasons for entering the role and stigma experiences: A preliminary report. Psychology of Men \& Masculinity 11: 279-285.

16. Dillaway H, Paré E (2008) Locating mothers: How cultural debates about stayat-home versus working mothers define women and home. Journal of Family Issues 29: 437-464.

17. Arendell T (1999) Hegemonic motherhood: Deviancy discourses among employed mothers with school-age children. Center for Working Families, University of California, Berkeley CA.

18. Dunn MG, Rochlen AB, O’Brien KM (2013) Employee, mother, and partner: An exploratory investigation of working women with stay-at-home fathers. Journal of Career Development 40: 3-22.

19. Etaugh C, Folger D (1998) Perceptions of parents whose work and parenting behaviors deviate from role expectations. Sex Roles 39: 215-223,

20. Riggs JM (1997) Mandates for mothers and fathers: perceptions of breadwinners and care givers. Sex Roles 37: 565-580.

21. Okimoto TG, Heilman ME (2012) The "Bad Parent" Assumption: How Gende Stereotypes Affect Reactions to Working Mothers. Journal of Social Issues 68: 704-724. 
Citation: Berger, L., Caluori, N., Pintar, M., Sinemus, S., Conley, L, et al. (2018) College Students' Attitudes towards Traditional and Nontraditional Parenting Roles: A Replication and Extension. J Ment Disord Treat 4: 153. doi:10.4172/2471-271X.1000153

22. LaRossa R, Gordon BA, Wilson RJ, Bairan A, Jaret C (1991) The fluctuating image of the 20th century American father. Journal of Marriage and Family 53: $987-997$

23. Heilman ME, Wallen AS, Fuchs D, Tamkins MM (2004) Penalties for Success: Reactions to Women Who Succeed at Male Gender-Typed Tasks. Journal of Applied Psychology 89: 416-427.

24. Bryant AN (2003) Changes in Attitudes toward Women's Roles: Predicting Gender-Role Traditionalism Among College Students. Sex Roles, 48: 131-142.

25. Cohen J (1992) A Power Primer. Psychological Bulletin, 112 155-159.

26. Eagly AH, Wood W, Diekman AB (2000) Social Role Theory of Sex Differences and Similarities: A Current Appraisal 123-161.

27. Barnett RC, Hyde JS (2001) Women, men, work, and family: An Expansionist theory. American Psychologist 56: 781-796.

28. Liss M, Erchull MJ (2012) Differences in Beliefs and Behaviors Between
Feminist Actual and Anticipated Mothers. Psychology of Women Quarterly 37 381-391.

29. Gere J, Helwig CC (2012) Young Adults Attitudes and Reasoning about Gender Roles in the Family Context. Psychology of Women Quarterly 36: 301-313.

30. Bonett DG (2012) Replication-Extension studies. Current Directions in Psychological Science 21: 409-412.

31. Barber JS (2001) Ideational influences on the transition to parenthood: Attitudes toward childbearing and competing alternatives. Social Psychology Quarterly 64: 101-127.

32. Baron RM, Kenny DA (1986) The moderator-mediator variable distinction in social psychological research: Conceptual, strategic, and statistical considerations. Journal of Personality and Social Psychology 51: 1173-1182.

33. O'Reilly A (1996) Ain't that love? Antiracism and racial constructions of motherhood. In: Reddy MT (ed.) Everyday acts against racism. Seattle, WA: Seal Press 